\title{
Author Correction: Perivascular macrophages in health and disease
}

Antonio Lapenna, Michele De Palma $₫$ and Claire E. Lewis

Correction to: Nature Reviews Immunology https://doi.org/10.1038/s41577-018-0056-9, published online 20 August 2018.

The originally published article contained an error in the acknowledgements section in which the date of a RISE grant from the European Commission to C.E.L was incorrectly shown as 2018. The grant number has been corrected in the HTML and PDF versions of the paper to 'H2020-MSCA-RISE-2017'.

https://doi.org/10.1038/s41577-021-00630-y I Published online 21 September 2021

(c) Springer Nature Limited 2021 